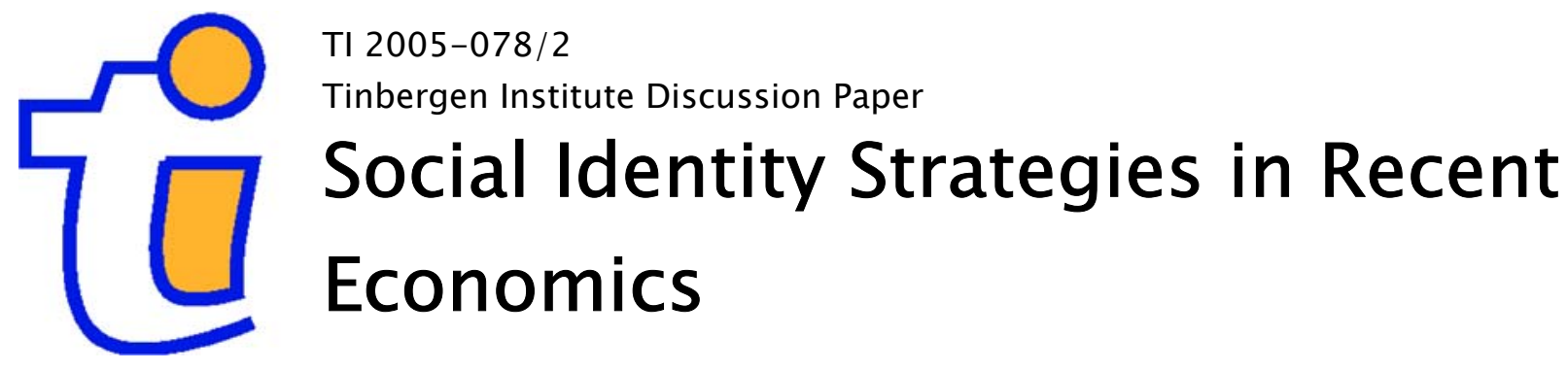

John B. Davis

University of Amsterdam, and Tinbergen Institute. 


\section{Tinbergen Institute}

The Tinbergen Institute is the institute for economic research of the Erasmus Universiteit Rotterdam, Universiteit van Amsterdam, and Vrije Universiteit Amsterdam.

Tinbergen Institute Amsterdam

Roetersstraat 31

1018 WB Amsterdam

The Netherlands

Tel.: $\quad+31(0) 205513500$

Fax: $\quad+31(0) 205513555$

Tinbergen Institute Rotterdam

Burg. Oudlaan 50

3062 PA Rotterdam

The Netherlands

Tel.: $\quad+31(0) 104088900$

Fax: $\quad+31(0) 104089031$

Please send questions and/or remarks of nonscientific nature to driessen@tinbergen.nl.

Most TI discussion papers can be downloaded at http://www.tinbergen.nl. 


\title{
Social identity strategies in recent economics
}

\author{
John B. Davis \\ University of Amsterdam and Marquette University
}

\begin{abstract}
This paper reviews three distinct strategies in recent economics for using the concept of social identity in the explanation of individual behavior: Akerlof and Kranton's neoclassical approach, Sen's commitment approach, and Kirman et al.'s complexity approach. The primary focus is the multiple selves problem and the difficulties associated with failing to explain social identity and personal identity together. The argument of the paper is that too narrow a scope for reflexivity in individual decisionmaking renders the problem intractable, but that enlarging this scope makes it possible to explain personal and social identity together in connection with an individual behavior termed comparative value-objective evaluation. The paper concludes with recommendations for treating the individual objective function as a production function.
\end{abstract}

Keywords: social identity, personal identity, reflexivity, individual objective function JEL Classification: D01, D63, Z13

Most economists believe that economics at some level is about individuals, and take the idea of the individual to be basically unproblematic. Yet in economics today individuals can be single persons, groups of people, and the different selves of single persons. How are all these different kinds of 'individuals' related? Do the different selves of a single person make up that person in the same way that different persons make up a single group of people? Are the different selves of a person distinct in the same way as are the different persons that make up a group of people? Until recently, there has been little in economics that provides a systematic way of addressing these issues with the result that the main behavioral tool in economics meant to represent the idea of a single economic 
agent - the individual objective function - applies indistinguishably to individuals made up of many persons, single individuals, and even individuals' different selves. Indeed there is nothing in the concept of an individual objective function that tells us what it applies to in terms of number. Thus the decisions economists make about what individual objective functions apply to must be ad hoc in nature, and that economics cannot tell the difference between one person and many persons or between one person and a person's different selves means it lacks a way of saying how it hooks onto the world - indeed whether it hooks onto the world at all - a problem consistent with the now frequently expressed charge that economics today is unacceptably 'formalist.,

Recently, however, a number of strategies have emerged that innovate on past thinking by using the concept of social identity to simultaneously address two issues which might be seen as duals of one another:

I how a single person can have different selves understood as a person's different social identities;

II how different persons can make up a single social group understood as their shared social identity.

This paper first distinguishes and evaluates three different current strategies for using the concept of social identity in this way: one is neoclassical - Akerlof and Kranton's introduction of a concept of social identity drawn from social psychology into standard

\footnotetext{
${ }^{1}$ I argue in Davis (2003) that this outcome was produced by the progressive stripping out of subjective characteristics of the individual in the development of neoclassical economics from cardinal to ordinal to revealed preference theory, and that this outcome provides one way of distinguishing contemporary mainstream economics from neoclassical economics.
} 
utility function analysis; a second transforms the neoclassical framework - Sen's

reformulation of the theory of individual behavior by the introduction of a concept of commitment to social groups; a third abandons the neoclassical framework altogether Kirman and his colleague's complexity theory approach to individual behavior in social networks. Each of these different strategies is examined in terms of how they address the two issues above by linking social identity to personal identity, where this relationship is taken to be central to developing an adequate conception of the individual for economics. The paper then compares and evaluates these different strategies, and attempts to diagnose broad difficulties involved in linking personal identity and social identity. The focus is on issue I - standardly called the multiple selves problem - on the grounds that addressing issue II depends on first having an adequate account of personal identity. The argument the paper then makes is that the intractability of the multiple selves problem for the approaches surveyed here stems from adopting too narrow a scope for reflexivity in individual decision-making. If the scope of reflexivity rather includes the individual in her social identifications with others, an argument can be outlined to account for personal identity across individuals' involvement in different social groups. The paper concludes with brief comments on the implications of this possible argument for how the individual objective function might be re-conceived.

\section{$1 \quad$ Three social identity strategies}

Broadly speaking, social identity is an individual's identification with others, or the idea that the individual takes on a group identity by ascribing herself characteristics belonging to a group. That a person's individual characteristics are group characteristics, however, 
invites one to ask how the individual is still an individual. Do individuals also have characteristics specifically appropriate to them as individuals over and above those understood as group characteristics? Or, might the individual as an individual somehow be seen as an intersection of different collections of group characteristics? These sorts of questions introduce the problem of personal identity, the concept of which differs according to whether one approaches it from a social psychology or philosophy perspective. In social psychology, personal identity is understood in contrast to social identity as an individual's identity apart from others. In philosophy, personal identity is generally framed without reference to social identity, and addresses the question of how an individual can change and remain the same individual. The latter concept can be framed in social identity terms if the ways in which an individual changes are seen to be a matter of that individual's changing social characteristics. The former concept can also be understood more along the lines of the latter if an individual's identity apart from others is understood more dynamically. From this combined perspective, social identity and personal identity are related matters, and while both concepts can and have been investigated separately to an extent, the views one develops on either score, however reasonable, ultimately have implications for the other concept that may or may not be reasonable. A question the recent literature in economics on social identity consequently raises is how do explanations of individuals having social identities relate to accounts of them as individuals, or how is social identity related to personal identity in economics?

While this issue seems to be a new one for economics, it nonetheless arises out of longstanding concerns with the nature of individual interaction. Traditionally, economics has not been seen as a theory of individual interaction on account of the mediating role of 
price in competitive markets, but recognition that competitive markets are a special case, combined with the rise of an explicitly interactionist form of explanation in game theory has made the nature of economics' longstanding concerns more clear. At the same time, minus the mediating role of price, the basis for the idea that individuals are separate and independent is no longer self-evident. The recent social identity literature in economics (cf. Kirman and Teschl, 2004) thus explores how individual autonomy might breakdown as a result of certain types of interaction between individuals associated with the phenomenon of social identification. This literature also represents an extension of past, interactionist concerns, albeit a particularly significant one, because it uses a core methodological modeling practice in economics - differentiating the exogenous from the endogenous - to examine the extent to which individuality is exogenous to individual interaction. This, then, is the connection in which the question of personal identity, or how individuality may be seen to be exogenous, arises in context of standard concerns.

\section{The neoclassical strategy}

Akerlof and Kranton (2000) introduce the concept of social identity into a neoclassical utility maximizing framework by treating a person's "sense of self" or "self-image" as an argument in a person's utility function. More fully, the self-image argument is a vector reflecting the different social categories (race, gender, etc.) that are assignable to the individual. Taken together, a person's "sense of self" or "self-image" is then said to make up her identity in that her "identity is bound to social categories; and individuals identify with people in some categories and differentiate themselves from those in others" (Akerlof and Kranton, 2000, p. 720; emphasis added). Thus 


$$
\text { (1) } U_{j}=U_{j} \quad\left(\boldsymbol{a}_{j}, \boldsymbol{a}-j, \boldsymbol{I}_{j}\right)
$$

Here utility depends upon $j$ 's identity or self-image $\boldsymbol{I}_{j}$ and also on $j$ 's actions $\boldsymbol{a}_{j}$ and the actions of others $\boldsymbol{a}-j$. Self-image itself is then defined as:

$$
\text { (2) } \quad \boldsymbol{I}_{j}=\boldsymbol{I}_{j}\left(\boldsymbol{a}_{j}, \boldsymbol{a}-j ; \mathbf{c}_{j}, \mathbf{c}_{j}, \mathbf{P}\right) \text {. }
$$

Identity or self-image depends again on $j$ 's actions and the actions of others, upon $j$ 's assignable social categories $\mathrm{c}_{j}$, and upon the extent to which $j$ 's own given characteristics $\mathbf{c}_{j}$ match the social ideals of $j$ 's categories, as indicated by recognized social prescriptions associated with those categories $\mathbf{P}$.

Note that self-image is not an image of the self per se or an image of the individual as a whole, but is rather an image of an aspect of the self, or more accurately, as $\boldsymbol{I}_{j}$ is a vector, a set of images of different aspects of the self associated with all the different social categories that are assignable to the individual. Akerlof and Kranton also offer a concept of the self, though they do not associate this with the idea of having a personal identity or otherwise use that concept. Most basically, the concept of the self they employ is simply the individual utility function (1), since in standard manner this serves to pick out each separate individual. But in the interpretation they give to this concept of the self, they draw on a generalized account of psychodynamic personality theory to treat the individual as an identity separate from all its different social identities.

This model can be expressed by ideas central to the psychodynamic theory of personality, found in almost any psychology text. In personality development, 
psychologists agree on the importance of internalization of rules for behavior. Freud called this process the development of the superego. Modern scholars disagree with Freud on the importance of psychosexual factors in an individual's development, but they agree on the importance of anxiety that a person experiences when she violates her internalized rules. One's identity, or ego, or self, must be constantly "defended against anxiety in order to limit disruption and maintain a sense of unity" (Akerlof and Kranton, 2000, p. 728; original emphasis).

Thus individuals themselves are identified as a 'personality,' 'ego,' 'self,' or 'sense of unity.' This self must be defended against anxiety, which Akerlof and Kranton explain as recurringly generated in interactions with others which create challenges to the individual's self-image. Individual responses to these challenges are explained game theoretically in terms of whether the internalized rules or social prescriptions associated with the social categories $\mathbf{P}$ assignable to the individual are somehow jeopardized by others' actions, thus generating anxiety for the individual, and then leading to actions meant to reduce this anxiety.

Akerlof and Kranton thus interpret the self and the individual utility function as an anxiety-reducing mechanism. The term 'mechanism' applies, because they "do not presume one way or another that people are aware of their own motivations, as in standard utility theory which is agnostic as to whether an individual shopper is aware or not of the reasons for her choices" (Akerlof and Kranton, 2000, p. 719). Further, the self is an anxiety-reducing mechanism, because its operation is restricted to relatively simple feedback principles that allow it to maintain self-image or social identity stocks, which are themselves taken as given or exogenous in terms of the categories $\mathrm{c}_{j}$ assignable to the individual. That these stocks are given or exogenous reflects Akerlof and Kranton's reliance on social psychology's 'social identity approach' that dates back to the work of 
Tajfel (e.g., Tajfel, 1972, 1981; cf. Abrams and Hogg, 1999). Tajfel defined social identity as "the individual's knowledge that he belongs to certain social groups together with some emotional and value significance to him of his group membership" (Tajfel, 1972, p. 292). The principal theory today within the 'social identity approach' is 'selfcategorization theory' of Turner, which explains how individuals act when they come to see themselves in terms of set social categories (Turner, 1985; Turner et al., 1987). On Turner's view, the social categories that apply to an individual are not constructed by the individual, but are the product of public discourse and the work of social scientists. Though social categories can of course change, at any one time a particular collection of them exists that constitutes an array of different, given social identities in terms of which individuals see themselves.

What understanding of the concepts of personal identity and social identity and the relationship between them, then, is implied by Akerlof and Kranton's analysis? First, the concept of the personal identity they employ is that of a single collection of selfimage stocks more or less maintained in given quantities by means of a thermostatic-type feedback rule. These stocks do not grow through investment, since the ones that apply to an individual are taken as given, and are accordingly neither transformable nor expandable in number by individual action. At the same time, the anxiety-reduction mechanism implies that individuals operate in such a way as to maintain their self-image stocks, or operate so as to prevent their depreciation. ${ }^{2}$ Thus Akerlof and Kranton offer a concept of personal identity in the philosophical sense of identity or sameness through

\footnotetext{
${ }^{2}$ This contrasts with Becker's analysis (1996) that allows for investment and depreciation in an individual's personal and social capital. Becker does not explicitly define personal capital in social identity terms. Further, his concept of social capital, which draws on Coleman (1990), is related to social network theory, and thus closer to the 'sociological approach to identity' (see below), though Becker does not make this connection either.
} 
change in terms of both a given set of self-image stocks and a regulatory principle governing their maintenance as a single, set collection. At the same time, they offer a concept of personal identity in the social psychology sense of individual identity apart from others in terms of the idea that each individual possesses one particular collection of social characteristics or self-image stocks that distinguishes that individual from others with whom she shares some social characteristics.

Second, then, the concept of the social identity Akerlof and Kranton employ is the idea of a correspondence between the individual characteristics of a person and the social characteristics of the social categories which exogenously apply to that person. As they frame it, social identity is the extent to which a person's individual characteristics $\mathbf{\epsilon}_{j}$ match the social ideals of the categories that apply to them, as indicated by recognized social prescriptions associated with those categories $\mathbf{P}$. This correspondence or matching concept of social identity may be contrasted with another also to be found in contemporary social psychology, namely the 'sociological approach to identity,' which originated in symbolic interactionist thinking of George Mead (1934), and which currently owes much to Stryker (1980). The central assumption of this approach is that individuals occupy locations within social structures, and that social identity is explained by how they are influenced by and also negotiate these social structures. ${ }^{3}$ Thus rather than use the 'social identity approach' idea of a correspondence or match between given social categories and individual characteristics to treat social identity as something an individual possesses, the 'sociological approach to identity' uses the idea of negotiated

\footnotetext{
${ }^{3}$ For a comparison of these two social psychology social identity approaches and additional references to the literature, see Hogg, Terry, and White (1995). For a discussion of Akerlof and Kranton's reliance on psychology's 'social identity approach' and the differences between it and the competing 'sociological approach to identity,' see Davis (2004). Akerlof and Kranton reference both Tajfel and Turner, but do not reference or draw on the sociological approach literature of Mead, Stryker, and others.
} 
social positions resulting from interaction between individuals in social structures to treat social identity as something individuals produce.

Finally, how are we to look upon the relationship between personal identity and social identity for Akerlof and Kranton? In their basic model, Akerlof and Kranton only explain how any particular social identity is related to personal identity, but do not explain how an individual's multiple social identities are all at once related to personal identity. They nonetheless recognize that it is important to extend their basic model, since "more realistically" individuals have many identities, and could "choose - more or less consciously - their identities as well as their activities" (Akerlof and Kranton, 2000, p.731). That is, there is a difference between a choice between identities and a choice between activities in defense of a single social identity (the subject of the basic model). However they also say that the former type of choice depends on the probability of different matchings between individuals and new social categories, or upon how the 'situations' in which individuals find themselves may change: "When an individual's identity is associated with multiple social categories, the 'situation' could determine, for example, which categories are most salient" (Akerlof and Kranton, 2000, p. 731n). ${ }^{4}$ Their example is when a firm possibly facing discrimination complaints creates new kinds of jobs appropriate to women, so that it then offers 'women's jobs' and 'men's jobs.' Women can now pursue 'women's jobs' where previously such jobs were unavailable. They can thus choose a new different social identity. This, however, is simply to say that when the social identity choice set is different, the individual may act on a different social identity. Women still only have a choice between different activities

\footnotetext{
${ }^{4}$ Also see their application of this reasoning to the topic of identity and schooling "which advances a notion of utility where an individual's identity, or sense of self, is salient" (Akerlof and Kranton, 2002, p. 1168.
} 
in defense of a single (newly salient) social identity as explained in the basic model. Social identity has simply exogenously changed with the 'situation.'

Ignored, then, is issue I above, that is, the possibility that individuals might need to choose between or otherwise organize their different social identities within a single social identity choice set prior to acting in defense of any one of them. This was the problem in the older multiple selves literature associated with trying to understand how an individual could be a single self yet have different utility functions (cf. Davis, 2003, chapter 4). Akerlof and Kranton effectively avoid this problem by offering a partial equilibrium type of analysis of identity that focuses on one social identity at a time, holding all others in an individual's self-image vector constant, so that the 'sense of unity' they refer to in representing the self has nothing to do with individuals having multiple selves at a point in time. But this means that they also fail to address issue II above, or how different persons can make up a single social group understood as their shared social identity. If personal identity in the social psychology sense is related to the particular collection of social identities each person has, then people are all different from one another by virtue of having different collections of social identities. But then saying that they share one collection of social characteristics is not enough to say how they share social identities, since there are also social characteristics they do not share. We might conclude, then, by offering the following diagnosis of why the Akerlof-Kranton strategy fails to successfully address the two issues here. Having made self-image or social identity exogenous, they are not in a position to either explain it or its relation to personal identity. 


\section{The commitment approach}

Sen introduces the concept of social identity into economics via the concept of commitment. Commitment is first characterized as a distinct form of behavior by contrasting it with sympathy, understood in standard neoclassical terms as self-interested utility maximization with interdependent preferences (Sen, 1977). Whereas sympathy involves a concern for others that affects one's welfare directly, in making commitments one's welfare is only incidentally related to one's choice and not the reason for it. Commitments, moreover, are often (though not exclusively) made to social groups, where they are associated with recognizing the "intrinsic importance ... attached to following certain rules of behavior" that operate in those groups (Sen, 2002, p. 217n). Sen thus links commitment and social identity or social identification, where he understands the latter specifically as "the idea of identifying oneself with others of a particular group" (Sen, 1999b, p. 2; original emphasis). From this perspective, commitment behavior can be seen to be fundamentally different from self-interested utility maximization behavior, because the latter is effectively a matter of 'identifying with oneself' while the former is a matter of 'identifying with others.' In contrast to Akerlof and Kranton, then, who expand the neoclassical framework by introducing social identity into it by adding a concept of self-image as an argument in the utility function, Sen transforms that framework by making utility maximization a special case in a more general theory of behavior that differentiates kinds of behavior according to who one identifies with and according to the relative weights placed on individual and social identity.

This more general theory of behavior is tied to Sen's view of the individual as a being able to engage in "reasoning and self-scrutiny" (Sen, 2002, p. 36). He defines the 
individual as a being able to act self-interestedly, able to reason about herself acting selfinterestedly, and able to reason about this goal and other goals all relative to one another:

A person is not only an entity that can enjoy one's own consumption, experience, and appreciate one's welfare, and have one's goals, but also an entity that can examine one's values and objectives and choose in the light of those values and objectives" (Ibid.).

Reasoning about one's own values and objectives and self-scrutiny, then, are inseparable aspects of one fundamental human behavior, because one can only evaluate one's different goals if one sees oneself as a being able to have different goals. Reasoning and self-scrutiny are thus associated with the "problem" of "the 'identity' of a person, that is, how the person sees himself or herself" (Sen, 2002, p. 215). Finally, personal identity, seen as the identity of a person in terms of how she sees herself, is linked to social identity in terms of how she chooses to make commitments to social groups, among all the other goals she chooses to act upon.

Social groups, of course, are different from social categories employed in the analysis of Akerlof and Kranton. Whereas individuals are assignable to the latter by third parties, individuals themselves make commitments to social groups that may then be examined by third parties. This difference is important in Sen's critique (Sen, 1999b, 2004) of the communitarian view that one 'discovers' what social identities one possesses as if one were to learn about certain personal endowments. On that view, the 'identifying with' meaning of social identity or social identification implies that the individual has essentially no ability to evaluate and reason about her attachments to different social groups which she might be assigned to in the eyes of society. That is, one's social 
identities are given exogenously to the individual. However, by regarding the individual as a being able to engage in reasoning and self-scrutinizing, Sen makes the individual's social identities endogenous to her choice and action. Others may assign the individual a particular social identity, but whether the individual actually identifies with that social identity is a matter about which the individual may reason and decide.

What, then, is Sen's understanding of personal identity $?^{5}$ Given his understanding of the behavior of the individual as reasoning and self-scrutinizing, the concept of personal identity he employs is of a being defined as having a capability to evaluate her own values and objectives. The idea of a capability, as explained subsequently to his thinking about commitment, is the idea of a freedom exercised with regard to some way of being or functioning that a being may possess (e.g., Sen, 1980, 1985). No specific set of capabilities can define personal identity, since in the case of the philosophical sense of personal identity, individuals must exhibit sameness through change, and an individual's capability set can change. However, if we regard the capability of being able to evaluate one's own values and objectives as a most basic human capability, personal identity can be seen to be this basic capability. Moreover, this basic capability constitutes personal identity in the social psychology sense as well, since there personal identity is identity apart from others or apart from one's social identifications, and this basic capability of being a reasoning and self-scrutinizing type of being is something that is not only exercised by the individual independently of others, but is also often exercised with respect to how one regards one's different possible social identifications.

\footnotetext{
${ }^{5}$ I have previously discussed this issue at greater length in Davis (forthcoming).
} 
Second, what is Sen's concept of social identity? It cannot be the idea of a match or correspondence between individual characteristics and social categories employed by Akerlof and Kranton, because reasoning, self-scrutinizing individuals evaluate when and how they choose to socially identify with others. That is, they play a role in determining whether a match between their own and social group characteristics applies, so that an individual's social identities are endogenous rather than exogenous to individual action. In the tradition of Mead and the 'sociological approach to identity,' this alternative concept of social identity might be termed interactionist in the sense that individuals' social identities are determined according to how they choose to interact with social groups. Note that the emphasis here lies entirely on what individuals do, and ignores how social groups might themselves evolve and change, and thus alter the basis on which individuals choose to interact with them. That is, the identity of social groups themselves is exogenous, though they are endogenous to individual choice and action. From this perspective, Sen's concept of social identity might be termed individual interactionist in that it holds constant this further dimension of interaction in its focus on the individual.

This, then, raises the issue of the relationship between personal identity and social identity. We saw above that the strong exogeneity assumption about social groups that Akerlof and Kranton make prevents them from addressing the multiple selves problem. Sen's understanding of the individual as reasoning and self-scrutinizing allows him in principle to address this problem, though he does not explain just how individuals order and negotiate their different social identities. It is quite possible that he believes that there is no systematic framework in which the individual can be explained as doing so - a view that would be analogous to his view that there can be no systematic ordering or 
ranking of individual capabilities. Thus we might say that, while on one level - the basic idea of the individual as a reasoning and self-scrutinizing being - Sen successfully solves issue I - how a single person can have different selves understood as a person's different social identities - on a second level he is agnostic about it. The matter is more serious with respect to issue II - how different persons can make up a single social group understood as their shared social identity. That, on the one hand, individuals can always opt out of social groups, while on the other hand the boundaries of social groups may change as a result of this means that we are in a poor position to explain how a social group can be an individual made up of many individuals. Sen might respond to this by reinterpreting the link suggested at the outset between issues I and II. Specifically, social groups are not individuals in the way that single persons are, so that it is enough to understand what an individual is to say how a single person has multiple selves.

\section{Complexity theory}

Much of complexity theory is independent of the question of how personal and social identity might be understood (cf. e.g., Arthur et al., 1997). However, one important source of complexity theory in economics lies in the critique of standard general equilibrium theory particularly as it pertains to the conception of the atomistic individual. Kirman has emphasized this connection, and argued that individuals may be better conceptualized as directly interacting with one another in social contexts rather than indirectly through markets (Kirman, 1992, 1997; cf. Davis, 2005). In more recent work of Kirman and his colleagues, this alternative view of the individual is explicitly linked to the problem of personal identity in economics understood both in the philosophical sense 
of identity or sameness through change and also in the social psychology sense of individual identity apart from one's social identifications with others (Kirman, 2005; Horst, Kirman, and Teschl, 2005; also cf. Kirman and Teschl, 2004). Here the particular idea adopted to represent the self is that of self-image, as in Akerlof and Kranton, though in contrast to their view, self-image is tied to individuals' involvement in social groups rather than to social categories. That is, individuals form self-images not in terms of social categories assignable to them by others but directly through their interaction with others in social groups. Specifically, individuals choose to belong to or participate in social groups with characteristics they believe fit their own, thus choosing a social image that comes closest to or coheres best with their own personal image of themselves. The coherence or incoherence - a kind of cognitive dissonance - between personal image and social image, then, is what motivates individual actions and choices.

However, there is a further difference from the Akerlof and Kranton view that is even more striking. Whereas Akerlof and Kranton use a utility function concept of the self, Horst, Kirman, and Teschl adopt the phenomenal self-model (PSM) approach to the self recently developed by Metzinger (2003). Metzinger's view, derived from his aim of combining neuroscience, psychology, and philosophy, is simple and straightforward: there is no such thing as a self in the world, and all that exists in connection with the term are our phenomenal selves or the sense we have of ourselves as appears in consciousness. Indeed because consciousness is constantly changing, the phenomenal self cannot be a thing but can only be an ongoing process.

My claim is that - ontologically speaking - no such things as selves exist in the world. What actually exists is a special kind of self-models and their contents, 
and this content makes us believe that we actually do have, or are identical to, a self (Metzinger, 2003, p. 626).

To explain our self-models, Metzinger develops a representationalist analysis of what consciousness of first-person perspective involves, where the representation of the self is simply one kind of representation-processing activity commonly found throughout the biological world, and which in the case of human beings is co-present with the representation of objects outside of the self. In effect, the sense of the self is immediate or internal to individual experience, or as he puts it in invoking the idea of a 'transparent' self, we see the world through ourselves in an automatically reflexive way. The Akerlof and Kranton strategy, in contrast, posits a self as a substantive entity as governed by an individual's preferences and utility function that exists over and above the phenomenal self.

Horst, Kirman, and Teschl combine the PSM approach with an interactionist or complexity theory view that assumes individuals are not only influenced by their social contexts and their membership in social groups, but also influence social contexts and these social groups by their actions, thereby creating feedback relations between selfimage and social context. Kirman (2005) thus emphasizes that accounts of individual behavior cast exclusively in psychological terms can only provide static accounts of personal identity, whereas more realistic models in which individuals are influenced by social contexts and then influence them as well offer the promise of explaining personal identity in dynamic terms. Moreover, since one's psychology, as it were, is itself changed by social interaction, this "puts into question immediately the notion of a utility function which is unchanging over time" (Horst, Kirman, and Teschl, 2005, p. 12). This 
all implies that in the more realistic type of setting personal identity needs to be modeled not only in terms of sameness or invariance, as in most traditional philosophical accounts, but also in terms of change. ${ }^{6}$ Kirman characterizes the situation the individual faces in this way:

His interaction with other people around him will have some influence on his characteristics. But because he has a specific self-image of who he wants to be, his characteristics will not be completely determined by those around him. He is, at least to some extent, able to choose to which social groups he wants to belong. However, by choosing a group or groups, he will change his own characteristics, and possibly also his self-image. Furthermore, the fact that other people may also choose the same group will modify the characteristics of the group. This may lead the individual to reevaluate his participation in the group and possibly move on to another group. The very structure of society and the groups which make it up will be modified by the changing evaluations and choices of all the individuals (Kirman, 2005, p. 24).

The issue of the identity of groups themselves thus emerges for the first time as an issue parallel to the question of personal identity, and since both individuals and groups are always in a process of change - indeed interactively so - it is fair to say that on the new view of personal identity expressed here the identities of both individuals and groups need to be simultaneously explained in terms of both invariance and change.

What, then, is the understanding of personal identity in this complexity approach? First, Kirman and his colleagues reject the traditional understanding of personal identity associated with the idea of entities enduring through change as too narrowly reliant on a concept of sameness and invariance and as mistakenly failing to include a concept of change appropriate to certain kinds of things better understood as processes. At best, they suggest, following Livet (2004), entities may endure in relatively selfsame states

\footnotetext{
${ }^{6}$ Horst, Kirman, and Teschl (2005) credit Livet (2004) for emphasizing this point on the argument that any concept of personal identity needs to be conceived in terms of a criterion that itself changes.
} 
within discrete time intervals, and these intervals might then be connected through a sort of chain-linking method such that individuals would then only retain loose long term identities as successions of related but non-identical selves. ${ }^{7}$ At the same time, Kirman and his colleagues still take the process idea of the self to be a personal identity concept, distinguishing it as a solution to successive selves problems encountered in Parfit's (1984) 'survival is what matters' argument that concludes that separate but related selves rules out using the concept of personal identity. Second, the particular, process idea of the self they use is that of a cognitive-dissonance reducer. Though the content of individuals' self-images and also their individual characteristics do not endure through change so as to provide a single unchanging personal identity, individuals may still be identified generally across change as always responding to incoherence between personal image and social image. This cognitive-dissonance reducing process concept of personal identity thus combines the ideas of sameness and change, and does so in a social group type of social context in which social group identity is similarly understood in process terms.

What is the complexity approach to social identity? We might characterize it as a hybrid combination of both the interactionist approach to social identity associated with the 'sociological approach to identity' and the matching or correspondence approach to social identity employed by Akerlof and Kranton associated with psychology's 'social identity approach.' The interactionist side is clear in the formal modeling of dynamic feedback effects between individuals and social groups. The matching or correspondence side follows from the analysis of individual behavior as cognitive dissonance-reducing.

\footnotetext{
${ }^{7}$ Relatedly, the chain-linking idea is currently used as an index concept in calculating real from nominal national income by in effect repeatedly updating base years.
} 
Specifically, individuals choose groups to identify with by choosing those social images that most probably match or correspond to the personal images they have of themselves. ${ }^{8}$ However, dynamic interaction between individuals and social groups constantly changes the basis on which individuals' personal images may match the social images of social groups they might identify with. Thus there is a constant reshuffling of how individuals match themselves to groups. In effect, then, the other side of the coin of a fully dynamical analysis of interaction between individuals and social groups is a very simple account of behavior in terms of the personal and social image match.

Finally, how do these views of personal identity and social identity relate to one another? Here the contrast with Akerlof and Kranton is instructive since Kirman and his colleagues explicitly reject the view of personal identity implicit in the former's reliance on the utility function as the individual's personal identity. We saw above that Akerlof and Kranton's utility function approach lacks sufficient structure to explain how individuals might order or organize their different social identities, and thus re-encounters the old multiple selves (issue I). In the complexity approach, however, the multiple selves issue is embraced rather than seen as a problem since on the new conception of personal identity as involving both sameness and change, individuals are not only a succession of different selves, but their succession of selves is a product of their interaction in social groups and multiple social identities. But can the multiple selves problem be set aside so easily? Or more to the point, is the concept of personal identity as involving change - since is what serves to set the multiple selves problem aside - still a concept of personal identity as Kirman and his colleagues believe?

\footnotetext{
${ }^{8}$ Groups that 'most probably match' because the analysis is stochastic.
} 
Here there are grounds for doubt as the Metzinger PSM approach rejection of the idea of the self as an entity is meant to eliminate the very basis for saying that a succession of selves still belongs to a single self, that is, that there is such a thing as personal identity. While individuals still always have a phenomenal sense of themselves as having a self, because this first person perspective, self representing type of processing is by definition always co-present with the representation of objects outside of the self, the change in those objects must also change the phenomenal self. Thus there is no self over and above a succession of phenomenal selves, as Metzinger argues. The proposed PSM-inspired addition of change to the concept of personal identity, then, really overwhelms the invariance component of the concept to create an intertemporal multiple selves problem alongside Akerlof and Kranton's static multiple selves problem. This also comes out in the modeling analysis Horst, Kirman, and Teschl (2005) employ which uses unchanging names for individuals and social types - the appearance of sameness but which makes clear that these names have changing referents. ${ }^{9}$

\section{$2 \quad$ Linking personal identity and social identity}

Here I evaluate these three different strategies for linking personal identity and social identity from the perspective of issue I, the multiple selves problem, on the assumption that it is more fundamental, and must be successfully addressed before one goes on to address issue II. First, then, compare the strategies of Akerlof and Kranton with Kirman and his colleagues. Despite their differences, both offer a psychology-based account of

\footnotetext{
${ }^{9}$ As is informally illustrated with respect to social types: "individuals make their choice between Republicans and Democrats, their choice set does not vary, even though what the labels in that set represent may change" (Horst, Kirman, and Teschl, 2005, p. 16). This additionally implies that issue II is not successfully addressed since group membership is continually changing.
} 
identity as self-image that makes cognitive dissonance reduction a motivator for individual choice. The former see this as utility-increasing; the latter reject utility function analysis, and see it as a simple rule of behavior. Both nonetheless see the individual as responsive or reactive in nature to interactions with others that may generate cognitive dissonance. However, explaining behavior in this way is arguably at the root of their inability to address multiple social identities, because a behavior that is responsive or reactive makes each individual interaction with others unique or specific to that particular interaction. Thus for Akerlof and Kranton all game theoretic interactions depend on the game's context and structure, and for Kirman and his colleagues choices of a social images always involve social groups continually different because of changing membership. The individual cannot but be fragmented across these multiple interactions, because the characterization of behavior as reactive provides the individual no means of acting across contexts.

Second, compare Sen's strategy to both cognitive dissonance strategies. Sen addresses the multiple selves problem directly, and provides a heuristic to explain its solution. I say a 'heuristic' because his view that individuals reason about their values and objectives and thereby engage in self-scrutiny does not involve an actual account of behavior, that is, an explanation of how they do this, but rather constitutes a claim that they can. Nonetheless this claim points toward a view of interaction with others and social identification that is not specific to context or particular interactions with others, and consequently holds out the promise that individual behavior might be described in such a way as to show how individuals behave in terms of multiple social identities. What, then, might this alternative behavioral account involve? Sen uses the classical 
concept of an agent as an active being or an independent source of action in contrast to the reactive view of the individual in the traditional utility framework. ${ }^{10}$ However, the contrast might rather emphasize the scrutinizing idea, or the reflexive relation which an individual has to her own values and objectives. That is, whereas the cognitive dissonance strategies basically model the individual and reactive behavior on a subject object basis, Sen's self-scrutinizing idea models this on a subject (subject - object) basis. ${ }^{11}$ That individuals' behavior, then, is based on seeing themselves acting in the context of interaction opens the door to the possibility that individuals act across their different social identifications, and thus have personal identities reflecting their crossgroup behavior.

At the same time, Sen's reflexivity relation seems to need formulation in slightly different terms if it is to make social identification a focus of 'self'-scrutiny. If economics' deep concern is the nature of individual interaction (as claimed at the outset here), where this makes the extent to which individuality is endogenous to individual interaction an issue, then the individual or self should always be seen as simultaneously separate from and socially identified with others, so that the individual 'self' is not the traditional atomistic self of neoclassical economics but rather a socially embedded one with social features associated with social identities. The 'self'-scrutinizing individual would then examine her values and objectives in each of her social contexts or social group involvements and also across those contexts and group involvements. That is, she

\footnotetext{
10 'I am using the term 'agent' ... in its older - and grander - sense as someone who acts and brings about change, and whose achievements can be judged in terms of her own values and objectives ..." (Sen, 1999, p. 19).

${ }^{11}$ Kirman and his colleagues would likely reject this characterization based on their adoption of Metzinger's view, which has reflexive aspects. But putting aside whether Metzinger offers a reflexivity view of the individual of the kind suggested here, their model's reliance on cognitive dissonance rather implies the standard subject-object basis for understanding behavior.
} 
would evaluate the values-objectives relation in one social group setting, evaluate the values-objectives relation in a second social groups setting (and so on), and evaluate all these values-objectives relations in relation to one another. For example, an individual might see that at her place of employment the value of fairness is associated with certain types of actions and objectives on her part, see in her neighborhood community that fairness is associated with certain other types of actions and objectives on her part, and then judge how the cases are similar and different according to context, in order to act on her single, general view of how fairness is associated with certain types of actions and objectives on her part. This expands the scope of reflexivity as follows:

$$
\mathrm{S}\left[\mathrm{S}_{1}(\mathrm{~S}-\mathrm{O}), \mathrm{S}_{2}(\mathrm{~S}-\mathrm{O}), \ldots\right]
$$

where $\mathrm{S}$ is a representation of the individual that provides a conception of personal identity across the $S_{n}(S-O)$ social group contexts in which the individual examines her own values and objectives.

Expanding the scope of reflexivity in this way arguably creates a framework for explaining behavior with more structure than in the case of Sen's S (S - O) representation of self-scrutinizing. Whereas a single own values-objectives evaluation must be open to a wide variety of behavioral views in regard to how individuals link their values and objectives, the expanded framework might be effectively domesticated by developing relatively simple rules of comparison across contexts to underlie decision rules, given any particular rule regarding how individuals link values and objectives in all contexts. Thus, when one context differs from another in terms of certain features, the values-objectives 
relation in question would be modified in some particular way as reflected in such a comparison principle to determine a particular choice for the individual. Individual behavior might then be characterized as 'comparative value-objective evaluation,' and while there are reactive elements of this type of account of behavior as in the cognitive dissonance strategies, that reactive quality is left open-ended at the level of perception of differences across social contexts. Whereas cognitive dissonance occurs when a perceptual threshold is achieved - whether or not the individual is aware of this perception of differences between contexts can be both unconscious and articulated. Sen's emphasis on individuals having a faculty of reason understood as a capacity to articulate reasons for action consequently continues to play a role in decision-making, while seeing behavior as rooted in a type of comparison-making also captures its more determinate, reactive side that the fact of human behavior as 'somewhat' predictable justifies assuming.

\section{Concluding remarks on the individual objective function}

I noted at the outset that the individual objective function in standard theory applies indistinguishably to individuals made up of many persons, single individuals, and even to individuals' different selves, and that this raises the issue of the realism of standard theory in connection with the referentiality of the individual objective function concept. Here, based on the discussion in the previous section, I briefly conclude with two claims regarding how this problem might begin to be addressed, and then make a general remark about our understanding of the individual in economics. 
First, the argument above regarding how the scope of individual reflexivity needs to be expanded makes a specific claim about what the concept of the individual and thus the individual objective function refers to. In contrast to the idea that they both refer to an individual's different psychological states, with an expanded view of reflexivity both would refer to an individual's different social identity states. The two views could be integrated were we to suppose that an individual's psychological states can still to be investigated in each of those different social identity states, but there the proper concept would be an individual's 'sub-objective' function. Thus, the individual objective function per se would refer to an individual with multiple selves, and the individual's 'sub-objective' function would refer to any one of those multiple selves. Were this new view of the individual objective function to be developed successfully at the behavioral level, then we would have one possible answer to issue I, the multiple selves problem. In terms of standard economic modeling practice, then, concept of the individual would be said to be referentially adequate were the modeler to specify the level of the objective function and the appropriate corresponding behavior.

Second, whereas individuals' 'sub-objective' functions might be represented in any of a number of ways in use in current work ranging from utility function approaches to simple decision rule approaches, it seems that the individual objective function per se involves a different type of representation associated with its higher-order character. In contrast to the old meta-preferences idea where individuals have preferences over different sets of preferences, here a different type of behavior applies to the individual objective function than applies to the individual's sub-objective functions, because an individual's objective with reflexivity expanded is to maintain a personal identity rather 
than act in some way in some social context on the assumption that one has a personal identity. Thus, the characterization of behavior appropriate to the individual objective function is that which captures individuals' efforts to maintain identity - something which cannot be guaranteed. I suggest accordingly that the individual objective function be represented in production function terms to reflect the idea of the individual actively expending effort to maintain or construct identity.

These two points about the individual objective function make our view of the individual complex in the sense of involving different kinds of ways in which individuals act that are related to one another according to the nature of their interaction with others. The old view of interaction in economics which de-emphasized the idea based on the arm's length nature of interaction in price-mediated competitive markets supported a view of individual behavior as non-complex or uni-dimensional. The contemporary view of interaction in economics is much richer, but it also calls for a richer view of human behavior to accommodate its individual and social aspects and the extent to which individuality is endogenous to social interaction. This paper attempts to lay out a way of thinking about this richer view by focusing on social identity and particularly on issue I as the key issue associated with that concept. When progress is made on issue I that is convincing and satisfactory for researchers concerned with it, hopefully then attention will move to its dual, issue II or how different persons make up multi-person individuals.

\section{References}

Abrams, D. and Hogg, M. (1999) Social identity and social cognition, Oxford: Blackwell. 
Akerlof, G. and Kranton, R. (2000) "Economics and Identity," Quarterly Journal of Economics, 115, 3: 715-753.

Akerlof, G. and Kranton, R. (2002) "Identity and Schooling: Some Lessons for the Economics of Education," Journal of Economic Literature, 40 (December): 1167-1201.

Arthur, W. A., Durlauf, S., and Lane, D. (1997) "Introduction," in Arthur, Durlauf, and Lane, eds., The Economy as an Evolving Complex System II, Reading: Addison-Wesley: $1-14$.

Becker, G. (1996) Accounting for Tastes, Chicago: University of Chicago Press.

Coleman, J. (1990) Foundations of Social Theory, Cambridge, MA: Harvard University Press.

Davis, J. (2003) The Theory of the Individual in Economics, London: Routledge.

Davis, J. (2004) “Akerlof and Kranton on identity in economics," Research Memoranda in the History and Methodology of Economics, University of Amsterdam.

Davis, J. (2005) "Complexity theory's network conception of the individual," Marquette University research paper.

Davis, J. (forthcoming) "Identity and Commitment: Sen's Conception of the Individual," Bernhard Schmid and Fabienne Peters, eds., Rationality and Commitment, Oxford: Oxford University Press.

Hogg, M., Terry, D., and White, K. (1995) "A Tale of Two Theories: A Critical Comparison of Identity Theory with Social Identity Theory," Social Psychology Quarterly, 58: 255-269.

Horst, U., Kirman, A., and Teschl, M. (2005) “Searching for Identity," Paper presented for the ASSA meetings, Philadelphia, January 2005.

Kirman, A. (1992) "Whom or What Does the Representative Individual Represent?" Journal of Economic Perspectives, 6 (2): 117-136.

Kirman, A. (1997) "The Economy as an Interactive System," in W. B. Arthur, S. Durlauf, and D. Lane, eds., The Economy as an Evolving Complex System II, Reading, Mass: Addison-Wesley.

Kirman, A. (2005) "Demand Theory and General Equilibrium. From Observation to Introspection A Journey Down the Wrong Road," Paper presented for the HOPE conference, Duke University, April 2005. 
Kirman, A. and Teschl, M. (2004) "On the Emergence of Economic Identity," Revue de Philosophique économique, 9 (1): 59-86.

Livet, P. (2004) “La pluralité cohérente des notions d' identité pour les sciences sociales," Revue de Philosophique économique, 9 (1): 29-57.

Mead, G. (1934) Mind, self, and society, Chicago: University of Chicago.

Metzinger, T. (2003) Being No-one: The Self-Model Theory of Subjectivity, Cambridge, MA: MIT.

Parfit, D. (1984) Reasons and Persons. Oxford: Clarendon Press.

Sen, A. (1977) "Rational Fools: A Critique of the Behavioral Foundations of Economic Theory," Philosophy and Public Affairs, 6: 317-344.

Sen, A. (1980) "Equality of What?" in S. McMurrin, ed., Tanner Lectures on Human Values, vol. I, Salt Lake City: University of Utah Press and Cambridge: Cambridge University Press.

Sen, A. (1985) Commodities and Capabilities, Amsterdam: North Holland.

Sen, A. (1999a) Development as Freedom, New York: Knopf.

Sen, A. (1999b) Reason before Identity, New Delhi: Oxford University Press.

Sen, A. (2002) Rationality and Freedom, Cambridge, MA: Belknap Press.

Sen, A. (2004) “Social Identity,” Revue de Philosophique économique, 9 (1): 7-27.

Stryker, S. (1980) Symbolic interactionism: A social structural version, Menlo Park, CA: Benjamin/Cummings.

Tajfel, H. (1972) "Social categorization," in S. Moscovici, ed., Introduction à la psychologie sociale, Vol. 1, Paris: Larousse: 272-302.

Tajfel, H. (1981) Human Groups and social categories: Studies in Social Psychology, Cambridge: Cambridge University Press.

Turner, J. (1985) "Social Categorization and the Self-Concept: A Social Cognitive Theory of Group Behavior," in E. Lawler, ed., Advances in Group Processes: Theory and Research, Vol. 2, Greenwich, CT: JAI: 77-122.

Turner, J., Hogg, M., Oakes, P., Reicher, S., and Wetherell, M. (1987) Rediscovering the Social Group: A Self-Categorization Theory, Oxford: Blackwell. 